Research Article

\title{
Acoustic Emission Characteristics of Normal and Layered Concrete Blocks during Dilating/Static Fracture
}

\author{
Ji Ma, ${ }^{1,2}$ Feng Du $\mathbb{D}^{1,2,3}$ and Shuai Zhang ${ }^{4}$ \\ ${ }^{1}$ School of Energy and Mining Engineering, China University of Mining and Technology (Beijing), Beijing 100083, China \\ ${ }^{2}$ School of Emergency Management and Safety Engineering, China University of Mining and Technology (Beijing), \\ Beijing 100083, China \\ ${ }^{3}$ Department of Civil Engineering and Engineering Mechanics, Columbia University, New York, NY 10027, USA \\ ${ }^{4}$ School of Civil Engineering, Beijing Jiaotong University, Beijing 100044, China \\ Correspondence should be addressed to Feng Du; fengducumtb@126.com
}

Received 9 August 2019; Revised 19 November 2019; Accepted 13 December 2019; Published 8 January 2020

Academic Editor: Paolo Andrea Carraro

Copyright (c) 2020 Ji Ma et al. This is an open access article distributed under the Creative Commons Attribution License, which permits unrestricted use, distribution, and reproduction in any medium, provided the original work is properly cited.

\begin{abstract}
Static fracturing technology is one of the most effective methods for localized breaking of rock and concrete. Layered concrete and rock structures are commonly seen in engineering applications such as breaking of concrete buildings, stone cutting, and excavation of rock in underground spaces. Therefore, it is essential to study the static fracturing characteristics of layered concrete to ensure the safety of engineering construction processes. In this paper, using acoustic emission (AE) technology and surface displacement monitoring, the deformation and fracturing of ordinary-strength concrete, concrete with a soft interlayer, and layered concrete (with strength decreasing successively by layer) were studied under the effect of a static (or soundless) cracking agent (SCA). The experimental results indicated that (1) AE activity of the two layered concrete test blocks during static fracturing showed a gradually increasing trend, while that of the ordinary-strength concrete tended to first increase and then decrease; (2) for the concrete test block with a soft interlayer sandwiched by high-strength layers, the AE events reached a maximum in the transfer of expansion pressure stage, which accounted for $47.11 \%$ of the total value in static cracking; the macroscopic damage to layered concrete test blocks comprising multiple interlaid layers with different strengths mainly occurred in the fracturing stage, during which the $\mathrm{AE}$ events and $\mathrm{AE}$ energy accounted for $76.22 \%$ and $66.94 \%$, respectively, of those in the whole static fracturing process; and (3) the duration of static fracturing prolonged with the increase of the overall strength of the concrete test blocks. The results provide a useful experimental reference for the application of static fracturing technology in the breaking of layered concrete and rock.
\end{abstract}

\section{Introduction}

Concrete plays an extremely important role in engineering construction and is widely used as a large-scale artificial building material in many industrial practices, for example, civil engineering, mining, and water conservancy [1-5]. Hence, the behavior of concrete with respect to damage and fracture is highly significant and research into such behavior provides valuable guidance for the application of structures made from this material. In engineering, static cracking technology is widely used in complex environments, where blasting cannot be applied $[6,7]$. In such situations, a static (or soundless) cracking agent (SCA) is used to crush the body to be broken.

An SCA expands and thereby generates compressive stress within the surrounding media. When the compressive or tensile stresses in a particular direction exceed the tensile strength of the material, the material develops cracks. As the expansion pressure continues to increase, the cracks in the crushed material gradually propagate so that the material finally bursts apart (and the material is thus irreversibly crushed). As the technique requires that the SCA has a high crushing efficiency, is safe to use, and does not damage the environment [8,9], it has been highly utilized by 
construction companies. The static fracturing of concrete is particularly important and is attracting a great deal of attention in academic circles.

Acoustic emission (AE) is a phenomenon in which energy is released in the form of elastic waves when a material is deformed or fractured under the influence of an external or internal force [10-12]. For brittle materials like concrete, AE testing is therefore an effective method of evaluating the degree of damage incurred, locating fracturing positions, and predicting instability. Thus, it is a current hotspot in this field of research [13-15].

In light of the static fracturing characteristics of concrete, Gambatese [8] used a small-scale soundless chemical demolition agent (SCDA) to investigate the controlled cracking of concrete. The results showed that using an SCDA in this manner was able to increase the migration of the cracks, leading to an overall increase in crack length. Laefer et al. [9] investigated the static fracturing of concrete and analyzed the time taken for the first crack to appear, the minimum demolition time, and the maximum cumulative crack width after a 24-hour period. Cho et al. [16] modeled the initiation and propagation of cracks using the static crack method from a theoretical perspective and applied their work to the demolition of plain concrete. Moreover, they explored the minimum pressure required for plain concrete demolition. Tang et al. [17] explored the characteristics of concrete static fracturing using physical experiments and numerical simulations. They thus reproduced the whole process in the concrete (crack initiation, growth, and coalescence) under the effect of the SCA.

Other scholars also studied the static fracturing of rock and concrete under the effect of SCDAs and derived some important conclusions [18-20]. As for research on the AE characteristics associated with the static fracturing process in concrete, most of the existing studies have focused on AE in concrete under loading conditions [21-27]. Little research has been conducted on $\mathrm{AE}$ in concrete during static fracturing. Moreover, in some excavations using static fracturing (e.g., building demolition, precious stone cutting, and some special environments unsuited to traditional explosive blasting), the concrete or rock mass is not a single structure, and there exist multiple layers or weak interlayer structures; however, the research on the dilating/static fracture characteristics of layered concrete has been sparse; therefore, it is clear that the characteristics of the AE occurring during the static fracturing of layered concrete are in urgent need of study.

In this study, an SCA composed of calcium carbonate and calcium oxide was used to investigate $\mathrm{AE}$ in three different concrete test blocks (ordinary-strength concrete, concrete with a soft interlayer, and layered concrete). The results were used to compare and analyze the characteristics of the formation and development of microcracks in the different concrete blocks during static fracturing according to the changes occurring in the AE parameters. Moreover, the characteristics of signals recorded during the fracturing of the concrete were investigated quantitatively. By linking these with the change in displacement induced by macroscopic cracking processes, the relationships between displacement, AE, and time before and after the fracturing of the blocks could then be revealed.

\section{AE Experiments}

2.1. Sample Preparation. A wooden mold measuring $500 \times 500 \times 300 \quad$ (length $\times$ width $\times$ thickness, measured in $\mathrm{mm}$ ) was made for this study. It was equipped with five plastic pipes (each measuring $34 \mathrm{~mm}$ in diameter and $300 \mathrm{~mm}$ in length), as shown in Figure 1.

2.1.1. Preparation of Traditional Concrete Test Blocks. Common Portland cement (32.5 grade), medium sand (fineness in the range of 2.3-3.0), and gravel (diameters 5-40 $\mathrm{mm}$ ) were used as raw materials. Using these, C40 (ordinary-strength concrete) and C40-C10-C40 (concrete with a soft interlayer) test blocks were constructed. Here, C40 corresponds to concrete whose standard compressive strength is $40 \mathrm{MPa}$ (as stipulated in the Code for Design of Concrete Structures (GB50010-2010), common concrete is classified into 14 grades. C40 corresponds to a cubic concrete block with the side length of $150 \mathrm{~mm}$ prepared under standard curing conditions at a temperature of $20 \pm 2^{\circ} \mathrm{C}$ and relative humidity exceeding $95 \%$ for $28 \mathrm{~d}$, whose ultimate compressive strength satisfies $40 \mathrm{MPa} \leq f_{\text {cu }}, k<45 \mathrm{MPa}$ when tested using the standard method). The specific proportions and amounts of materials required to mix the two kinds of concrete are given in Table 1. Five holes were cast in each test block. To avoid outflow of the SCA under load, the holes needed to have a bottom of about $20 \mathrm{~mm}$ thick. The prepared C40 and C40-C10-C40 test blocks are shown in Figure 2.

2.1.2. Preparation of the Layered Concrete Test Block. In this work, cement was used as the cementing material, which increases the strength indices of the blocks of similar materials, thus meeting the needs of the current experiments. Cement has high strength and can be laid layer-by-layer (the minimum thickness of a layer is $3 \mathrm{~mm}$ ). It produces layers that bear a high similarity to layers simulating real strata, and cement can be used for simulation purposes over a large range of ratios, up to $1: 10$. High-alumina cement and Portland cement were utilized as the cementing materials in this work. Quartz powder was used as aggregate, and the components were mixed accordingly. To accelerate the hardening of the mixed materials, a quick setting agent was also adopted. In this way, a concrete test block consisting of 12 layers (each $25 \mathrm{~mm}$ thick) was produced. The specific mixing proportions and amounts of materials required for each layer are listed in Table 2 [28]. The final processed concrete block with 12 layers is shown in Figure 3.

2.2. Experimental System and Equipment. The instruments used in the experiments include an $\mathrm{AE}$ acquisition unit, an AE preamplifier unit, a concrete structures-AE sensor monitoring unit, and a micrometer. The schematic diagram of the experimental system is displayed in Figure 4. 


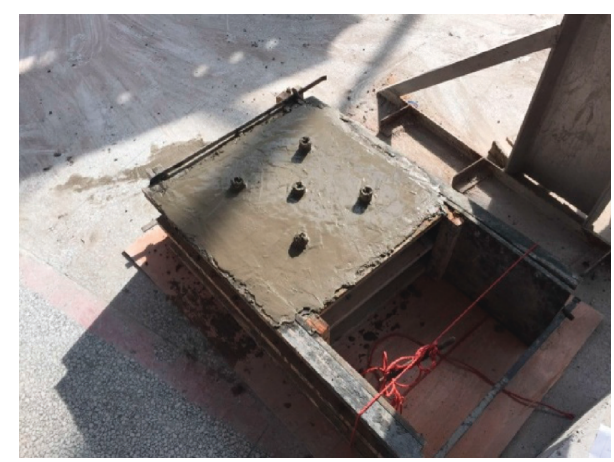

Figure 1: The mold used in the experiments.

TABLE 1: Mixing proportions used to prepare the different concrete samples.

\begin{tabular}{lcccc}
\hline Strength grade & \multicolumn{4}{c}{ Amount of material $\left(\mathrm{kg} / \mathrm{m}^{3}\right)$} \\
& Cement & $\begin{array}{c}\text { Fine } \\
\text { aggregate }\end{array}$ & $\begin{array}{c}\text { Coarse } \\
\text { aggregate }\end{array}$ & Water \\
\hline C40 & 520 & 525 & 1220 & 178 \\
Mixing & 1 & 1.01 & 2.35 & 0.34 \\
proportion & 185 & 876 & 1114 & 185 \\
$\begin{array}{l}\text { Mix } \\
\text { pixing }\end{array}$ & 1 & 4.74 & 6.02 & 1 \\
\hline
\end{tabular}

\subsection{Experimental Steps}

2.3.1. Layout of the AE Sensors. The AE sensors need to be appropriately arranged with respect to the holes in order to accurately monitor the AE signals produced during microcrack formation. Considering the robustness of the sensor fixtures, effects of macrocracking, and characteristics of the layered test block, the sensors were distributed over the four sides of the block using the diagonal formation shown in Figure 5. The AE sensors were fixed onto the faces of the block using special fixtures and grease was smeared over the porcelain surfaces of the sensors to act as a coupling agent. The spatial coordinates of the sensors are shown in Table 3.

\subsubsection{Setting the Monitoring Parameters of the AE Software.} As the experiments were conducted in a simulation hall, the blocks were unavoidably subjected to random background noises. Therefore, a series of tests were carried out before conducting the main AE experiments. Typical activities that could interfere with the apparatus were carried out (e.g., walking around the block, hitting the ground nearby, dropping heavy objects, etc.) and an appropriate threshold was determined for the system that met the specified experimental requirements. More specifically, the threshold was set to $70 \mathrm{mV}$ in the experiments reported here.

(i) Determination of the timing parameters

Pencil lead breaking (PLB) tests were adopted to determine the timing parameters. As shown in Figure 6, an AE sensor was attached to one face of a test block and the pencil lead broken on the opposite face (as a reproducible AE source). Each PLB test was repeated six times, generating $18 \mathrm{AE}$ signals in total from the three different kinds of test blocks. Table 4 lists the rise-times of the signals acquired.

The timing parameters required were derived by referring to the relevant standards and principles. For the first two types of concrete test blocks, it was found that the peak definition time (PDT) should be set to $200 \mu \mathrm{s}$, the hit definition time (HDT) to $400 \mu \mathrm{s}$, and the hit lockout time (HLT) to $500 \mu \mathrm{s}$. The corresponding timing parameters for the layered concrete test block with 12 layers are $\mathrm{PDT}=210 \mu \mathrm{s}$, $\mathrm{HDT}=420 \mu \mathrm{s}$, and $\mathrm{HLT}=500 \mu \mathrm{s}$.

(ii) Equipment debugging and material mixing/loading

After completing the initial preparation outlined above, the $\mathrm{AE}$ analyzer was turned on and the AE software run in "nonstorage" mode. A screwdriver was used to tap different locations around each fixed $\mathrm{AE}$ sensor to ensure that the maximum amplitude for each sensor could reach about $9,900 \mathrm{mV}$ (in the "state information" column in the software). This indicates that the $\mathrm{AE}$ sensors are completely coupled to the surface of the test blocks and that the $\mathrm{AE}$ signals received by the sensors are real.

The SCA ( $5 \mathrm{~kg}$ in each bag) was mixed with 1.5 to $2.5 \mathrm{~kg}$ of water. After being stirred sufficiently, the mixture was poured into the holes preset in the concrete test blocks (experiments were performed on the three types of test blocks according to their strengths). Afterwards, the AE data acquisition software and micrometer software were run to record the displacement every 30 seconds. As this took a long time, a large amount of data would be generated if continuous recording was employed. To overcome this problem, the AE acquisition software was set to collect data either intermittently or continuously.

\section{Experimental Results}

The test blocks were cracked and damaged to different degrees at different times by the SCA. Due to the different strengths and particularities of the layers in the three groups of test blocks, the final cracking patterns are different, as shown in Figure 7.

In the early stages, the SCA causes microcracks to be generated inside the test blocks. These then propagate, open up, close, and become connected as the reaction continues. Throughout this process, the $\mathrm{AE}$ sensors receive many different AE signals due to the microfracturing occurring. Thus, the characteristics of the microcrack-induced AE activity associated with the damaging or splitting of the different test blocks subjected to expansion pressure could be analyzed. In this work, the AE event count and cumulative $\mathrm{AE}$ event count data were combined with the explicit variation in the displacement recorded using micrometers. Based on the characteristic parameters derived for the $\mathrm{AE}$ energy count, the differences in the AE characteristics shown by microcrack development in the layered and intact test blocks could then be compared and analyzed. 


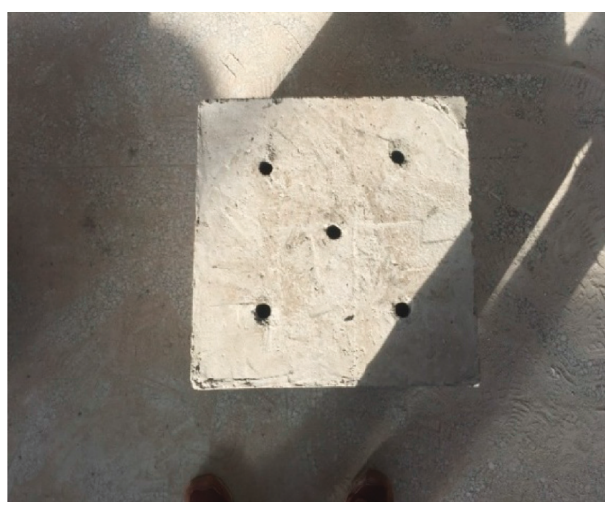

(a)

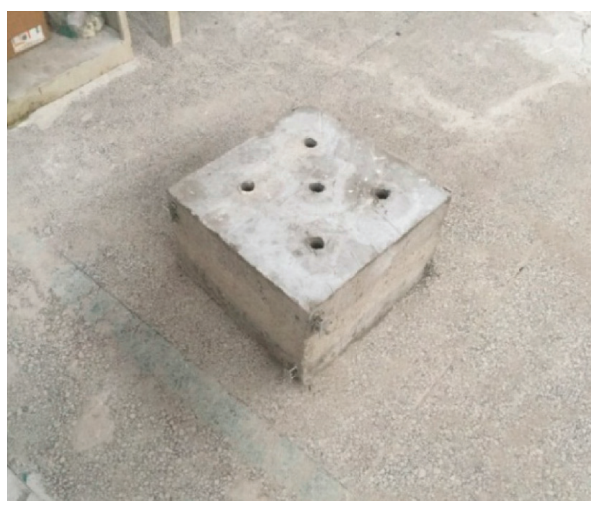

(b)

Figure 2: Concrete test blocks ready for testing: (a) C40; (b) C40-C10-C40.

TABLE 2: The mixing proportions used to create the layered concrete test block [28].

\begin{tabular}{|c|c|c|c|c|c|c|c|c|}
\hline \multirow[b]{2}{*}{ Material } & \multirow{2}{*}{$\begin{array}{c}\text { Compressive } \\
\text { strength }(\mathrm{MPa})\end{array}$} & \multirow{2}{*}{$\begin{array}{l}\text { Setting time } \\
\quad(\min )\end{array}$} & \multirow{2}{*}{$\begin{array}{l}\text { Proportion (by } \\
\text { weight) }\end{array}$} & \multicolumn{5}{|c|}{ Mass of material $(\mathrm{kg})$} \\
\hline & & & & $\begin{array}{c}\text { High-alumina } \\
\text { cement }\end{array}$ & $\begin{array}{c}\text { Portland } \\
\text { cement }\end{array}$ & $\begin{array}{l}\text { Quartz } \\
\text { powder }\end{array}$ & Water & $\begin{array}{c}\text { Quick setting } \\
\text { agent }\end{array}$ \\
\hline Sandstone & 13 & 10 & $1: 2: 6.47: 3.05$ & 1.15 & 2.30 & 7.45 & 3.51 & 0.104 \\
\hline $\begin{array}{l}\text { Sand- } \\
\text { shale-1 }\end{array}$ & 6 & 15 & $1: 2: 9: 4.1$ & 0.88 & 1.76 & 7.90 & 3.60 & 0.079 \\
\hline $\begin{array}{l}\text { Sand- } \\
\text { shale-2 }\end{array}$ & 4 & 20 & $1: 2: 14.5: 6.15$ & 0.59 & 1.18 & 8.56 & 3.63 & 0.053 \\
\hline Sandstone & 13 & 10 & $1: 2: 6.47: 3.05$ & 1.15 & 2.30 & 7.45 & 3.51 & 0.104 \\
\hline $\begin{array}{l}\text { Sand- } \\
\text { shale-1 }\end{array}$ & 6 & 15 & $1: 2: 9: 4.1$ & 0.88 & 1.76 & 7.90 & 3.60 & 0.079 \\
\hline Hard coal & 1.6 & 30 & $1: 2: 25: 11$ & 0.35 & 0.69 & 8.68 & 3.82 & 0.031 \\
\hline Sandstone & 13 & 10 & $1: 2: 6.47: 3.05$ & 1.15 & 2.30 & 7.45 & 3.51 & 0.104 \\
\hline $\begin{array}{l}\text { Sand- } \\
\text { shale-1 }\end{array}$ & 6 & 15 & $1: 2: 9: 4.1$ & 0.88 & 1.76 & 7.90 & 3.60 & 0.079 \\
\hline Sandstone & 13 & 10 & $1: 2: 6.47: 3.05$ & 1.15 & 2.30 & 7.45 & 3.51 & 0.104 \\
\hline $\begin{array}{l}\text { Mud } \\
\text { shale }\end{array}$ & 3 & 25 & $1: 2: 17.5: 7.18$ & 0.50 & 1.01 & 8.81 & 3.62 & 0.045 \\
\hline $\begin{array}{l}\text { Sand- } \\
\text { shale-1 }\end{array}$ & 6 & 15 & $1: 2: 9: 4.1$ & 0.88 & 1.76 & 7.90 & 3.60 & 0.079 \\
\hline Sandstone & 13 & 10 & $1: 2: 6.47: 3.05$ & 1.15 & 2.30 & 7.45 & 3.51 & 0.104 \\
\hline
\end{tabular}

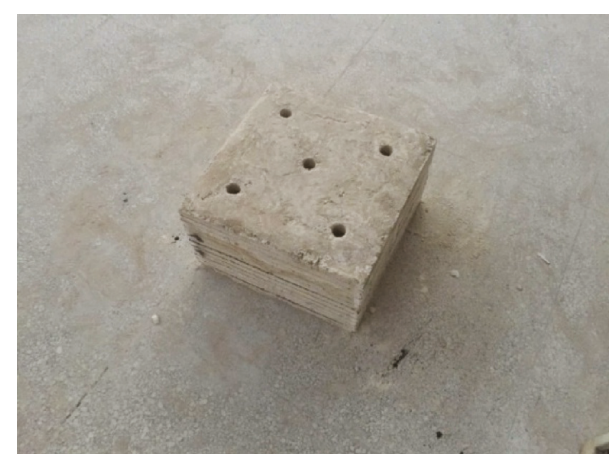

FIgURE 3: The layered concrete test block ready for testing.

3.1. AE Results for Test Blocks Subjected to Expansion Pressure. In Figures 8-10, we present the variation of the AE event count, cumulative AE event count, and displacement in each direction with time for the three types of test blocks.
The figures show the changes in AE event counts and displacement at single time points, which are used to reveal the degree of fracturing of the test blocks at different stages of static fracturing; the figures also demonstrate the changes in cumulative $\mathrm{AE}$ event counts with the duration of fracturing and allow analysis of changes in the fracturing characteristics of the test blocks under effects of expansion pressure generated by the SCA.

In general, the failure of rock or concrete under expansion pressure (i.e., pressure generated on the wall surrounding a hole by the reaction of the SCA) can be divided into three stages: a microfracturing stage, a transfer of expansion pressure stage, and a fracturing stage. The microfracturing stage can be further subdivided into elastic and nonlinear elastic stages. It has been suggested that concrete conforms to elastic laws for about $0-10 \mathrm{~h}$ when subjected to the effects of an SCA [29]. The latter can be regarded as a thick-walled cylinder subject to elastic mechanics for the 


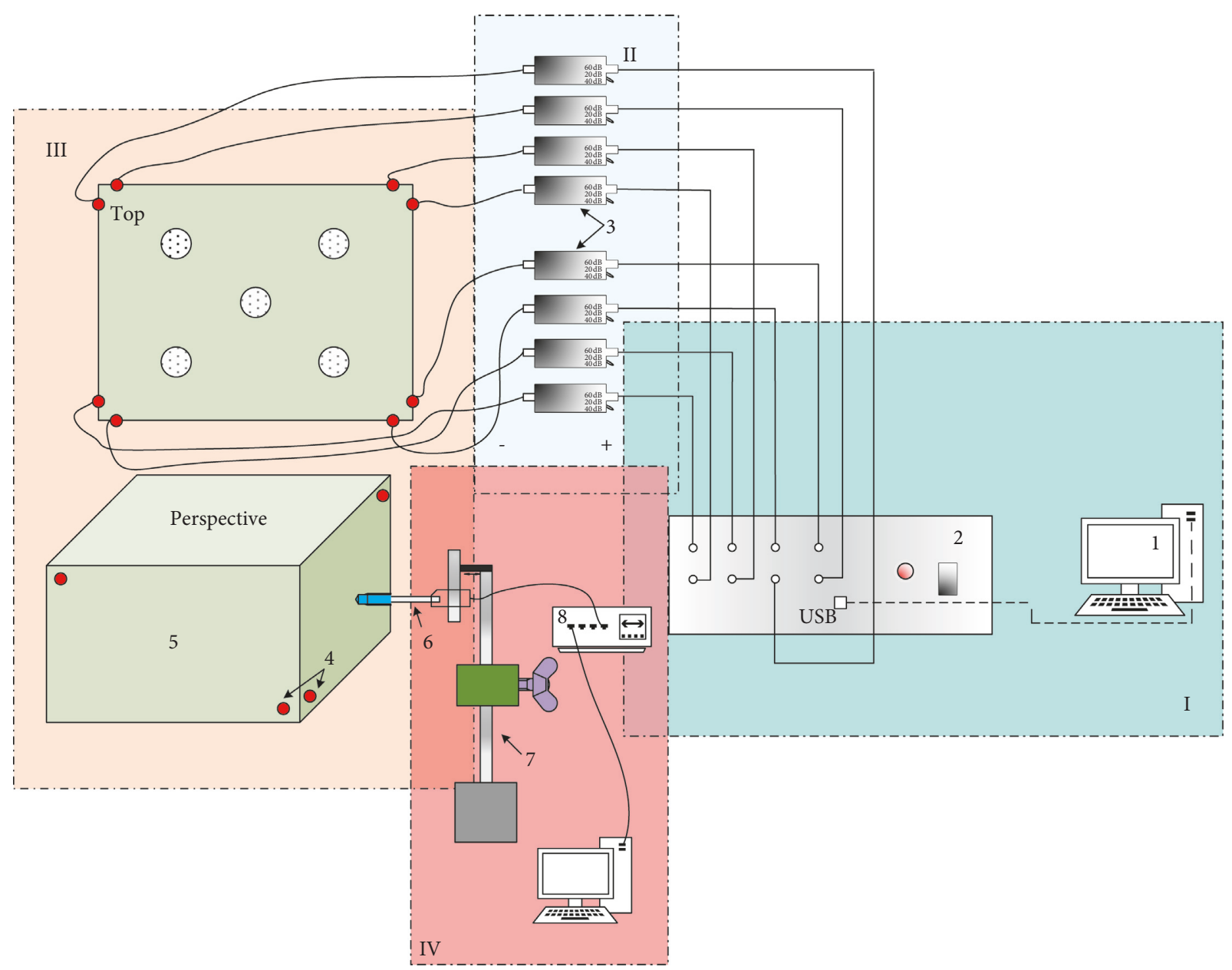

FIGURE 4: Schematic diagram of the experimental system. I (acoustic emission acquisition unit): (1) desktop computer (signal display) and (2) AE system (8 channels); II (acoustic emission preamplifiers unit): (3) AE preamplifiers (20/40/60 dB); III (monitoring unit of concrete structures and AE sensors): (4) AE sensors (frequency range: 50-400 kHz, center frequency: $150 \mathrm{kHz}$ ) and (5) concrete blocks; IV (micrometer unit): (6) micrometers, (7) fixed support, and (8) data acquisition instrument.

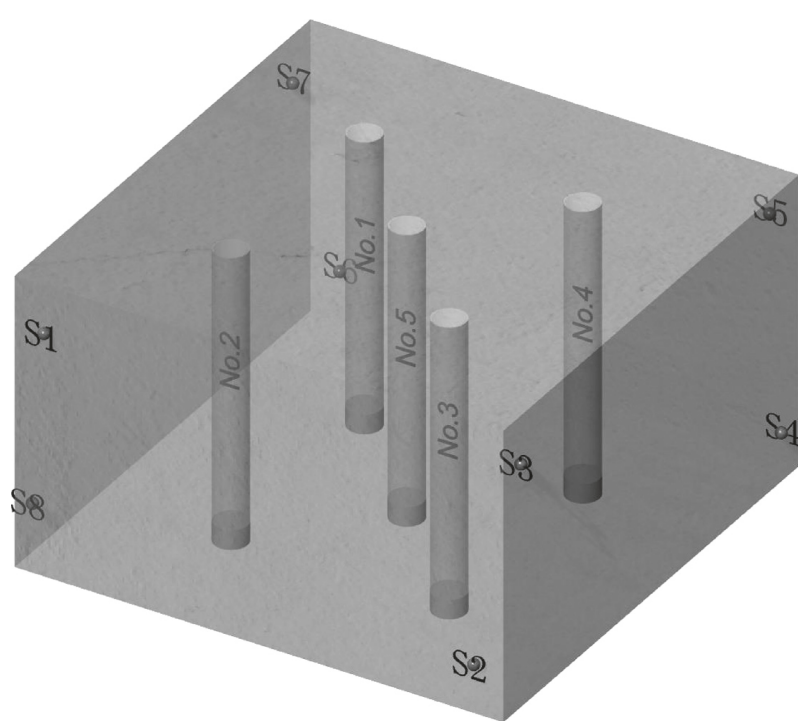

FIGURE 5: Schematic diagram showing the layout of the AE sensors (S1-S8).
TABle 3: The spatial coordinates of the points at which the sensors were attached to the test blocks.

\begin{tabular}{lccc}
\hline Sensor & $X(\mathrm{~mm})$ & $Y(\mathrm{~mm})$ & $Z(\mathrm{~mm})$ \\
\hline S1 & 30 & 0 & 250 \\
S2 & 470 & 0 & 50 \\
S3 & 500 & 30 & 250 \\
S4 & 500 & 470 & 50 \\
S5 & 470 & 500 & 250 \\
S6 & 30 & 500 & 50 \\
S7 & 0 & 470 & 250 \\
S8 & 0 & 30 & 50 \\
\hline
\end{tabular}

purposes of mechanical analysis (for more details, the reader can refer to the relevant literature [29]). After this time, when the expansion pressure has risen to a certain critical value, the inner walls of the hole are beginning to become damaged and a "damage zone" gradually develops. The formation of a damage zone releases some of the stress that has built up. At the same time, the expanding volume of the SCA continues to gradually increase with time and so the 


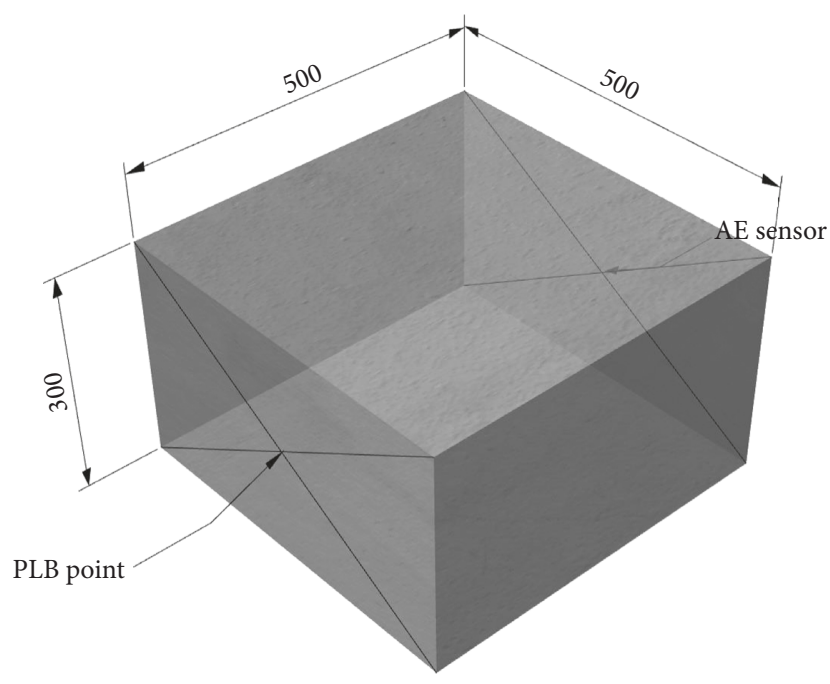

FIgURE 6: Schematic diagram showing the locations of the leadbreak point and $\mathrm{AE}$ sensor.

TABle 4: The rise-time data recorded in the PLB tests.

\begin{tabular}{|c|c|c|c|}
\hline \multirow[b]{2}{*}{ Block } & \multicolumn{3}{|c|}{ Rise-time $(\mu \mathrm{s})$} \\
\hline & $\begin{array}{c}\text { C40 } \\
\text { concrete }\end{array}$ & $\begin{array}{c}\mathrm{C} 40-\mathrm{C} 10-\mathrm{C} 40 \\
\text { concrete }\end{array}$ & Block with 12 layers \\
\hline 1 & 166.33 & 188.3 & 198.1 \\
\hline 2 & 173.35 & 175 & 208.33 \\
\hline 3 & 175 & 190.67 & 208.33 \\
\hline 4 & 174.67 & 175 & 206.35 \\
\hline 5 & 166.67 & 185.21 & 206.21 \\
\hline 6 & 169.33 & 188.3 & 209.27 \\
\hline
\end{tabular}

expansion pressure propagates away from the hole using the damage zone as a "medium." This is generally regarded to be the "transfer stage" of the expansion pressure. There is a large amount of AE activity when the damage zone forms due to the appearance of large numbers of microcracks. The evolution from the development to the propagation of the microcracks right up to the cracking of the test blocks can be used to discuss crack propagation from the perspective of fracture mechanics (which is a mature field of study). In the fracturing stage, the expansion pressure reaches a free surface. If there are multiple holes (as in the current experiments), different damage patterns or splitting states can occur.

Due to limitations imposed by the dimensions of the test blocks, experimental conditions, and other relevant factors, the changes occurring in the different test blocks during the static crushing process were discussed using a combination of $\mathrm{AE}$ technology and surface displacement changes based on theory developed by Jin et al. [29]. As the data were stored intermittently, about $1,895 \mathrm{~min}$ of $\mathrm{AE}$ data were collected during the experiment involving the $\mathrm{C} 40$ concrete test block (as this block has the highest strength). In contrast, only about $817 \mathrm{~min}$ of AE data were recorded for the C40-C10C40 block. Finally, because the layered concrete test block has the least strength of all the blocks used, only about 380 min of AE data were recorded for this block.
Based on the data shown in Figures 8-10, the following conclusions are made:

(1) For the C40 test block, the first $310 \mathrm{~min}$ can be considered to correspond to the elastic part of the microfracturing stage under the effect of the expansion pressure. During this period, the AE event counts are low and so the cumulative $\mathrm{AE}$ event counts increase only very slowly, the corresponding curve lying very close to the time axis. The displacement of the face containing the AE sensors S5$\mathrm{S} 6$ is zero in the positive $y$-direction, while the displacement of the face containing S3-S4 also does not change in the positive $x$-direction. Therefore, the nonlinear elastic part of the microfracturing stage must be considered to cover the period from 310 to $1,400 \mathrm{~min}$. In this stage, damage zones are formed around the holes due to the expansion pressure. As a result, there are frequent $\mathrm{AE}$ events and the $\mathrm{cu}$ mulative AE event counts clearly increase almost linearly as time goes by. Moreover, the S3-S4-containing face slowly starts to move in the $x$-direction (but the face containing S5-S6 remains essentially unmoved).

The transfer of expansion pressure stage covers from 1,400 to $1,780 \mathrm{~min}$. As the SCA continues to increase in volume and stress is released from the damage zone being formed, the AE event counts frequently jump in value (so the cumulative $\mathrm{AE}$ event counts suddenly surge upwards). In this stage, the displacement of the S5-S6-containing face suddenly and significantly begins to increase in the $y$-direction as time progresses. The S3-S4containing face also suddenly starts to move. Significant movement occurs for the first time in the range of 1,400-1,500 min. The displacement increases much more slowly over the period of 1,500-1,630 min. Thereafter, the displacement suddenly surges for the second time and shows the same linear increase as that of the S5-S6-containing face.

The period covering $1,780-1,895$ min can be considered to be the fracturing stage of the $\mathrm{C} 40$ concrete sample. During this stage, the AE event counts still jump frequently but there is a very large and sudden increase (to 1,936 counts) at about $1,821 \mathrm{~min}$. This is because there are five holes arranged within the test block and the expansion pressure acting on them eventually migrates to the free surface so that the damage zones become superposed with each other. This causes intense internal splitting to occur as cracks develop connecting the holes. As a result, the cumulative AE event counts suddenly increase. The face containing S5-S6 also moves more rapidly (in a nearly linear manner), while the displacement of S3S4-containing face only changes slightly.

(2) The C40-C10-C40 block contains a middle layer that is not as strong as the outer layers. Thus, the $\mathrm{AE}$ event counts, cumulative $\mathrm{AE}$ event counts, and 


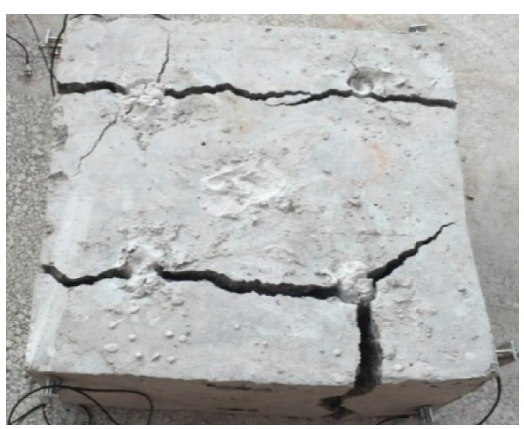

(a)

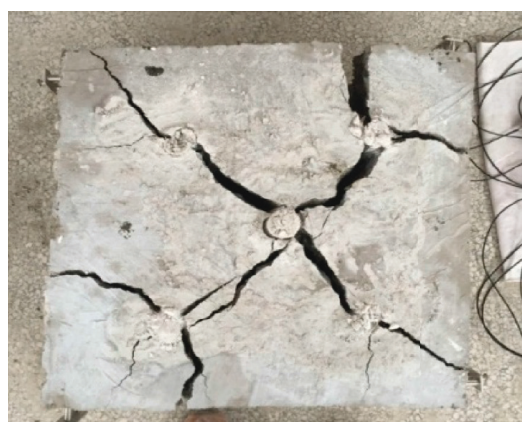

(b)

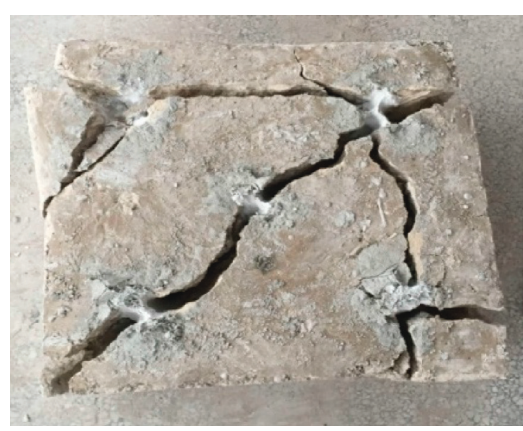

(c)

FIGURE 7: The fracturing observed in the test blocks: (a) C40; (b) C40-C10-C40; (c) layered concrete.

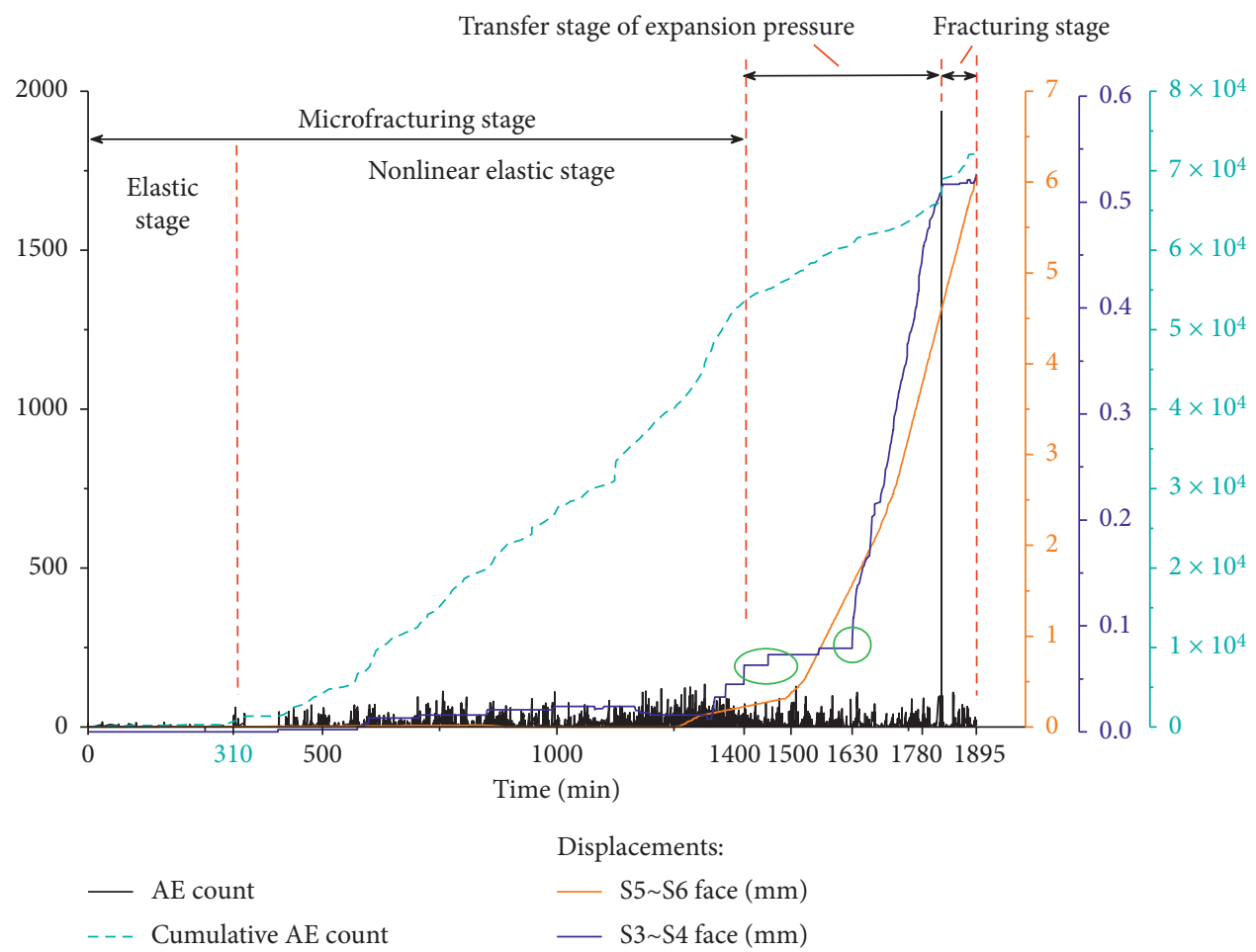

FIGURE 8: The relationships between displacement, AE event counts, cumulative AE event counts, and time before and after the fracturing of C40 concrete test block.

displacements recorded when static fracturing occurs are very different. In this case, the period of 0-200 min belongs to the elastic response stage of the microfracturing stage (and the $\mathrm{AE}$ event count, cumulative $\mathrm{AE}$ event count, and displacements show the same basic trends as those observed with $\mathrm{C} 40$ ). The nonlinear elastic stage of the microfracturing stage ranges from 200 to $400 \mathrm{~min}$. Here, the AE event counts are slightly increased (mostly remaining below 60), while the cumulative $\mathrm{AE}$ event counts begin to slowly rise. Moreover, the face containing the S1-S2 sensors starts to move in the positive $y$-direction at about $330 \mathrm{~min}$. The transfer of expansion pressure stage ranges from 400 to 600 min, wherein the AE event counts suddenly increase and reache a maximum value of 126 . Meanwhile, the cumulative AE event counts and displacement of the face containing S1-S2 rise steadily and constantly.

In the fracturing stage $(600-816 \mathrm{~min})$, the situation changes dramatically. This is especially demonstrated by the intense variation of the $\mathrm{AE}$ event counts and sudden growth of the cumulative $\mathrm{AE}$ event count. Furthermore, the AE event counts become relatively low and the cumulative $\mathrm{AE}$ event counts rise more slowly at about $750 \mathrm{~min}$. At this time, internal connections are being formed between the holes due to the expansion pressure. Cracks propagate and develop, causing the test block to crack, and these cracks propagate constantly. The 


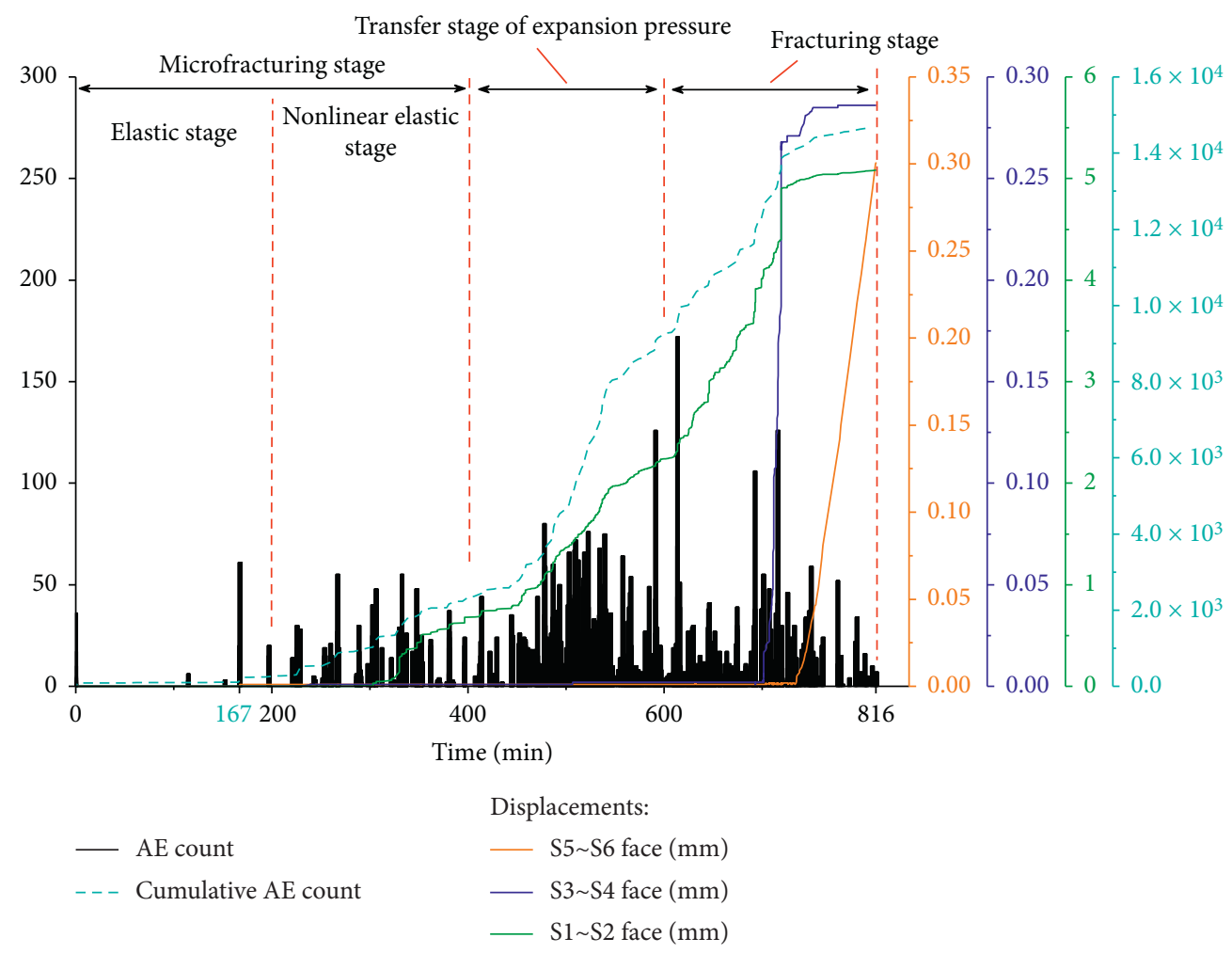

FIgURE 9: The relationships between displacement, AE event count, cumulative AE event count, and time before and after the fracturing of the C40-C10-C40 concrete test block.

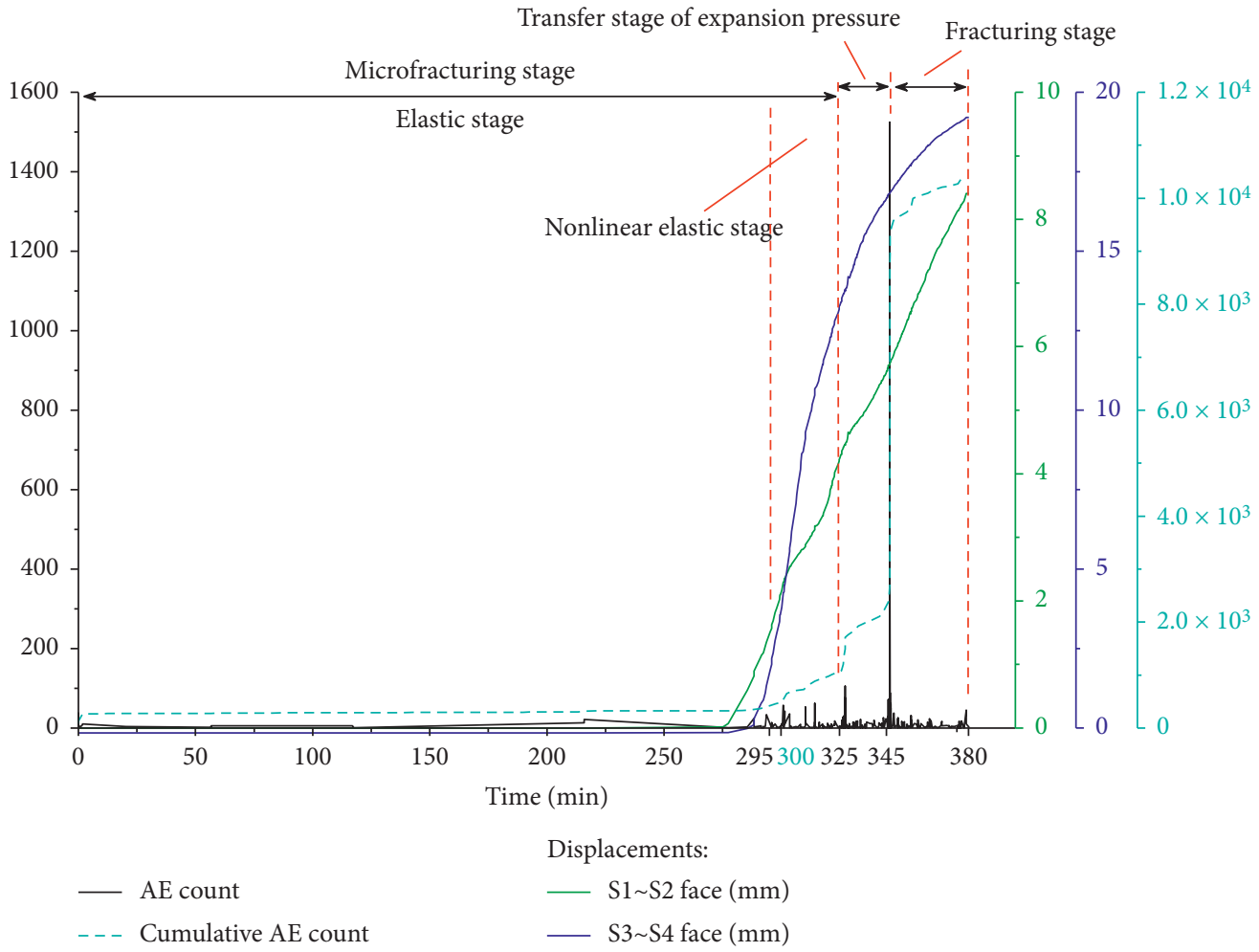

FIGURE 10: The relationships between displacement, AE event count, cumulative AE event count, and time before and after the fracturing of the layered concrete test block. 
displacement of the face containing S3-S4 suddenly increases at about $730 \mathrm{~min}$, after which it increases in a nearly linear manner. After $750 \mathrm{~min}$, this displacement essentially stops changing, proving that two holes near the free surface have become connected and the test block has cracked. In addition, after $750 \mathrm{~min}$, the displacement of the face containing S5-S6 increases linearly, while that of the face containing S1-S2 increases very slowly.

(3) The layered concrete test block consists of several (12) layers and has low strength. Thus, the block is rapidly split under the effect of the SCA. The same stages can once again be identified, including an elastic stage (0-295 min), nonlinear elastic stage (295-325 min), transfer of expansion pressure stage (325-345 min), and fracturing stage (345-380 $\mathrm{min}$ ).

This test block exhibits the same behavior in the elastic stage as that found previously in the other blocks. In the nonlinear elastic stage, the frequency of the AE event counts increases, leading to a small increase in the cumulative AE event counts. The faces containing S1-S2 and S3-S4 also begin to become displaced. The transfer of expansion pressure stage is relatively short because the gaps caused by the layering of the simulated strata allow the expansion pressure to easily migrate outwards. Microcracks quickly develop under the effect of the pressure, which rapidly turn into macrocracks, resulting in the test block splitting. In this stage, the AE event counts and cumulative $\mathrm{AE}$ event counts change violently, while the displacements grow steadily. In the fracturing stage, the $\mathrm{AE}$ event counts suddenly increase, while the cumulative $\mathrm{AE}$ event counts undergo a sudden increase at $350 \mathrm{~min}$, increase more slowly thereafter, and then stabilize. The displacement of the face containing S3-S4 starts to stabilize after $350 \mathrm{~min}$, while that containing S1-S2 continues to increase linearly with time.

(4) Comparing the three types of blocks, the first two involve significant displacement in the nonlinear elastic stage (of the microfracturing stage); the layered concrete block experiences significant displacement in the transfer of expansion pressure stage. Unlike the first two types of blocks, the layered test block mainly experiences $\mathrm{AE}$ events in the transfer of expansion pressure and fracturing stages.

In the layered block, the cumulative $\mathrm{AE}$ event counts suddenly surge in the transfer of expansion pressure stage, presenting more violent changes than those occurring in the C40 and $\mathrm{C} 40-\mathrm{C} 10-\mathrm{C} 40$ blocks. This indicates that macrocracks appear in the test block at this time and each hole becomes connected to the others. The cracks then develop towards the free surfaces under expansion pressure, causing serious damage.

3.2. Analysis of AE Energy. Figures 11-13 illustrate the energies of the $\mathrm{AE}$ signals recorded during the static fracturing processes presented as a function of time. The important stages in the static fracturing process have also been clearly marked in these figures. By comparing the changes observed in the $\mathrm{AE}$ energies, the following conclusions can be made:

(1) The emission of energy in the test carried out on the layered concrete block mainly occurred during the transfer of expansion pressure and fracturing stages. In the fracturing stage, the expansion pressure develops to reach the free surface and the holes inside the block become connected, thus forming macroscopic cracks. This is highly consistent with the variation of the $\mathrm{AE}$ event count. In other words, as each layer of the layered medium has different mechanical properties, the energy slowly builds up and accumulates with the formation of macrocracks and appearance of damage zones in the microfracturing stage. As the expansion pressure migrates outwards, pressure is transferred to strata that have relatively low strengths. Energy is therefore dissipated leading to a highly discrete release of energy at that time. In the fracturing stage, there is an abnormal and sudden release of energy as almost all of the energy accumulated inside is released to the outside. This damages the sample, after which the energy emission gradually falls again in the later stage of the fracturing process.

(2) Comparing the (ordinary-strength) C40 block with the C40-C10-C40 block (which contains a weak interlayer), the most energetic $\mathrm{AE}$ events in the former case are highly discrete and mainly distributed throughout the nonlinear elastic stage. When the transfer of expansion pressure and fracturing stages is reached, the $\mathrm{AE}$ energies are more densely distributed but their energies are relatively small (below $2,000 \mathrm{mV} * \mathrm{~ms}$ ). This suggests that many microcracks are produced in the inner walls of the holes due to the expansion pressure in the early stages of the formation of the damage zones, so that energy is accumulated to different degrees at that time. When the transfer of expansion pressure stage is reached, the expansion pressure migrates outwards, accompanied by energy dissipation. Hence, the amount of energy released is reduced.

(3) In the C40-C10-C40 block, the energies of the events are small, on average, and mainly concentrated in the three later stages (nonlinear elastic, transfer of expansion pressure, and fracturing stages). When the expansion pressure acts on the walls of the holes, the pressure is transferred to the weak C10 interlayer, which acts as a pressure-releasing zone preventing the accumulation of energy. Therefore, the energy released in the nonlinear elastic and transfer of expansion pressure stages is small. In the early fracturing stage, however, the pressure migrates outwards to the top and bottom layers as the weak interlayer has been damaged by the expansion pressure. In addition, there may be an abnormal and 
sudden release of some of the accumulated energy in the initial expansion of pressure stage due to the high strength of the outer C40 layers. Then, as damage is induced by the macrocracking of the test block, the energy dissipated in this concrete block gradually falls.

\section{Discussion}

The difference in the total time of receiving $\mathrm{AE}$ signals between these three concrete test blocks during the process of static fracture means that it is impossible to quantify the difference between $\mathrm{AE}$ event counts and energy dissipated between these three concrete blocks in each stage of static fracture. To ascertain the AE characteristics and energy changes in layered concrete blocks in the process of static fracture and to compare and analyze the difference between layered concrete and ordinary concrete conveniently, we separately counted the percentage of AE event counts and energy counts of these three kinds of concrete specimens in the microfracturing stage, transfer stage of expansion pressure, and fracturing stage and analyzed the changing trend in AE event counts and energy counts in each stage (Figures 14-16).

The cracking of C40 ordinary concrete blocks mainly occurs in the nonlinear elastic stage of microcracking stage, in which the $\mathrm{AE}$ event counts reach the maximum value, accounting for $73.51 \%$ of the total counts during the static cracking process. The energy released also shows the same trend, which indicates that when the monolithic ordinary concrete block does not form a macroscopic, large-scale failure, its internal crack or crack penetration is mainly concentrated in the nonlinear elastic stage from its yield limit to peak strength (Figure 14).

The C40-C10-C40 concrete block exhibits different fracture characteristics. AE signals are concentrated mainly on the large-scale failure of materials after reaching the peak strength, which is more in line with the failure characteristics of real crustal rock masses. The energy counts increase linearly during the whole process of static fracture. When the fracture stage is reached, macrofracturing occurs and the maximum proportion of released energy reaches $49.72 \%$; however, the number of fracture signals monitored by $\mathrm{AE}$ equipment reaches its maximum at the transfer stage of expansion pressure, accounting for $47.11 \%$ overall, which needs further study as to the causes of this abnormality. Nevertheless, on the whole, the AE event counts and energy count show an increasing trend during the whole static fracture process (Figure 15).

The strength of 12 layered concrete is lower than that of C40 ordinary concrete blocks, so the duration of static cracking of layered concrete is the shortest. Meanwhile, the $\mathrm{AE}$ event counts and energy released from fracture of specimen increase exponentially. Specifically, from the microcracking stage to expansion pressure transfer stage, the fracture signal and energy characteristics of layered concrete blocks increase linearly. The blocks are severely damaged and release a lot of elastic energy during the fracture stage. The proportions of AE event counts and energy counts reach

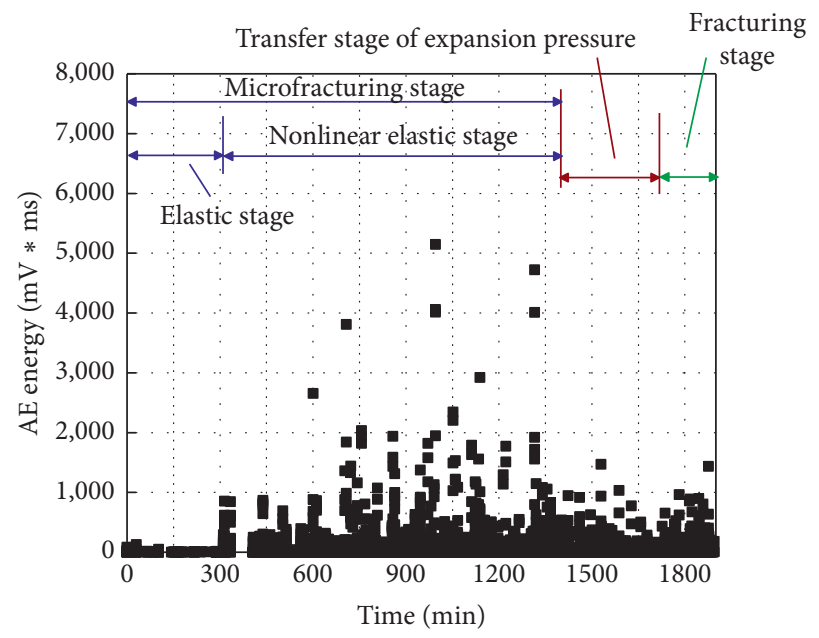

FIGURE 11: Scatter diagram showing the distribution of the $\mathrm{AE}$ energy detected during the static fracturing of the C40 test block.

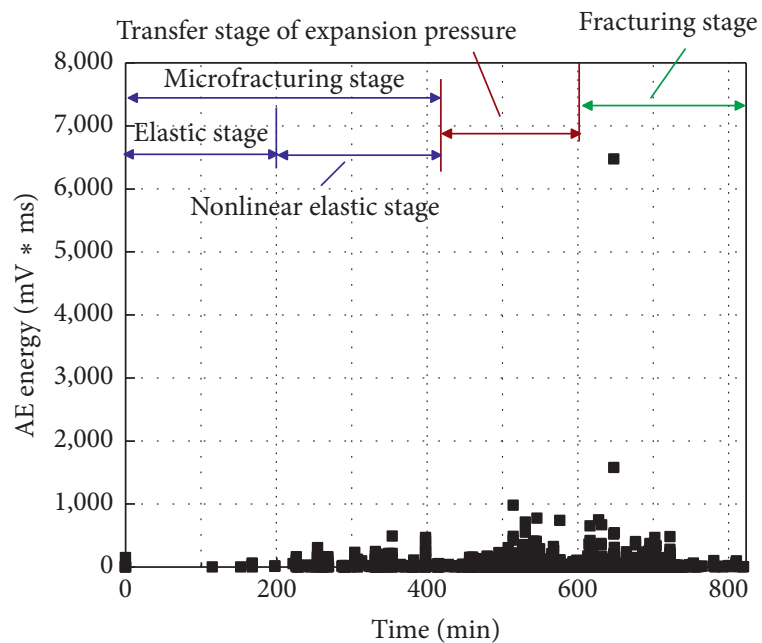

FIgURE 12: Scatter diagram showing the distribution of the $\mathrm{AE}$ energy detected during the static fracturing of the C40-C10-C40 test block.

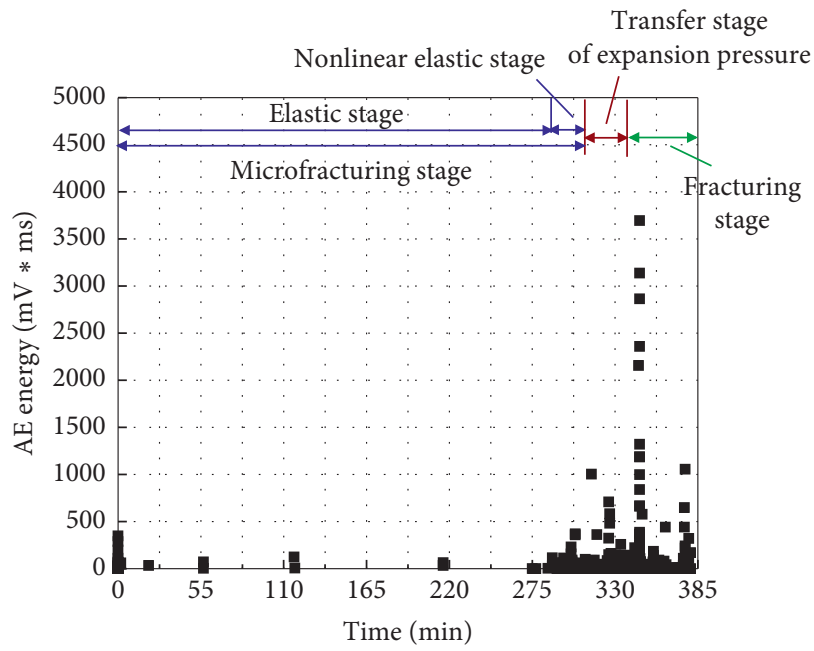

FIgURE 13: Scatter diagram showing the distribution of the $\mathrm{AE}$ energy detected during the static fracturing of the layered concrete block. 


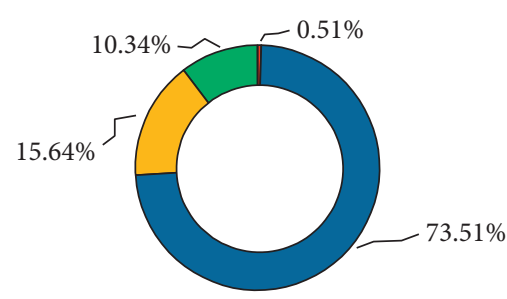

$\square$ E_s $\square$ Ept_s

$\square$ Ne_s $\square$ F_s

(a)

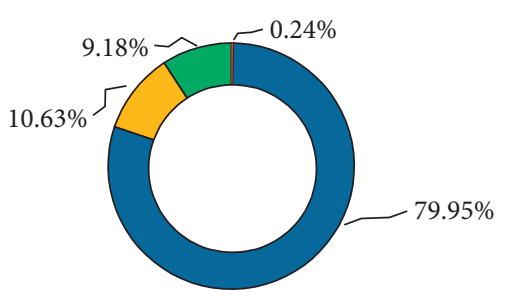

$\square$ E_s $\square$ Ept_s

$\square$ Ne_s $\square$ F_s

(b)

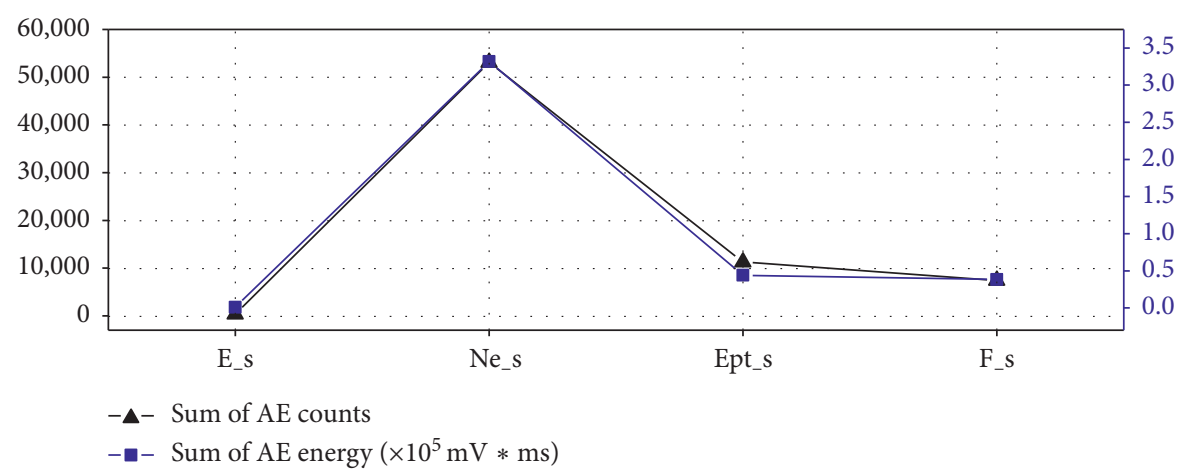

(c)

FIGURE 14: Trends of AE event counts and energy counts of C40 concrete blocks and their respective percentages: (a) percentage of AE event counts to total counts; (b) percentage of AE energy counts to total counts; (c) trends in AE event counts and energy counts. E_s: elastic stage; Ne_s: nonlinear elastic stage; Ept_s: transfer to expansion pressure stage; F_s: fracturing stage.



(a)

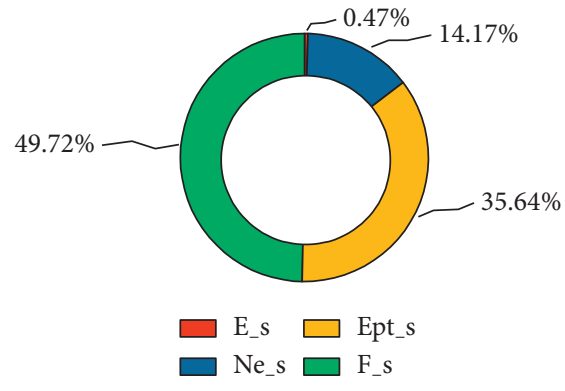

(b)

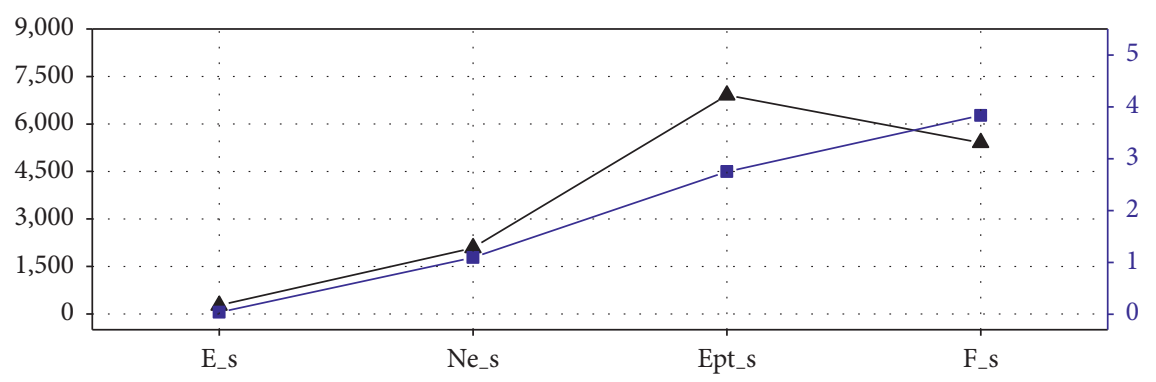

$-\mathbf{\Delta}-$ Sum of AE counts

- - Sum of AE energy $\left(\times 10^{4} \mathrm{mV} * \mathrm{~ms}\right)$

(c)

Figure 15: Trends in AE event counts and energy counts of C40-C10-C40 concrete block and their respective percentages (legends as per Figure 14). 


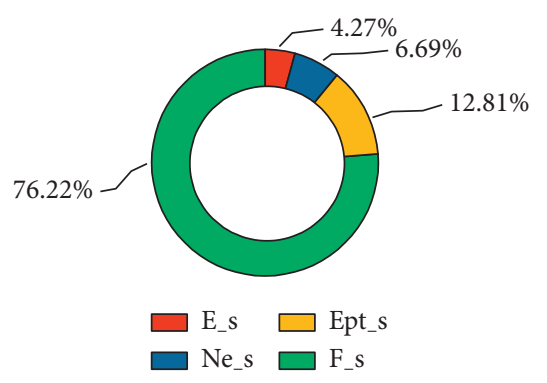

(a)

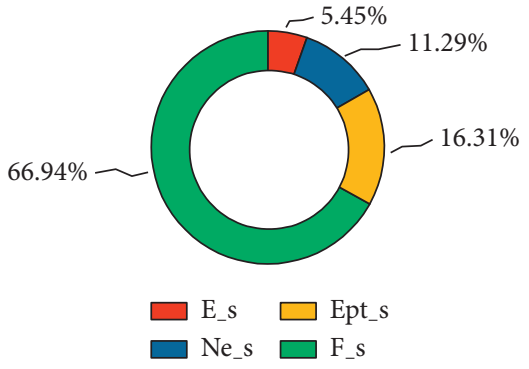

(b)

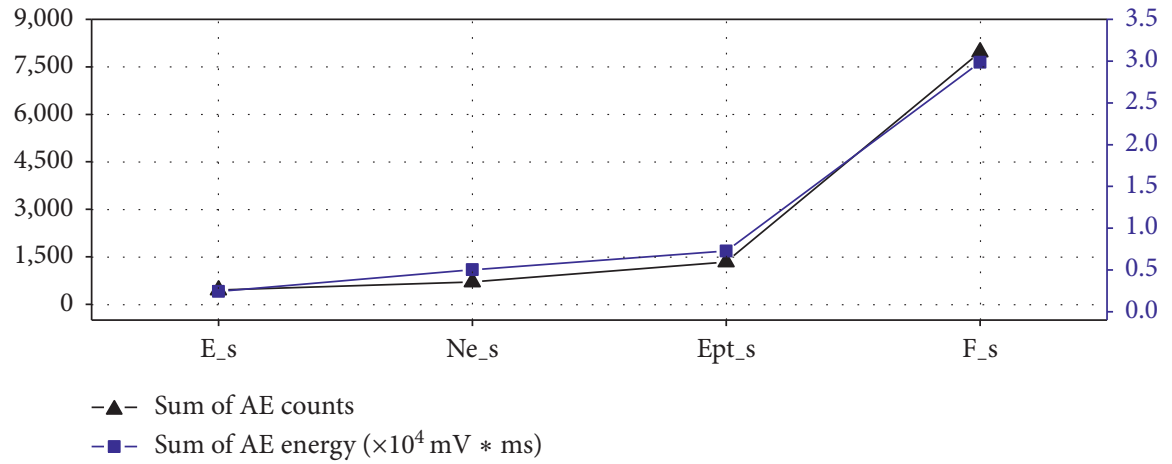

(c)

Figure 16: Trends in AE event counts and energy counts of layered concrete blocks and their respective percentages (legends as per Figure 14).

their maximum value, which account for $76.22 \%$ and $66.94 \%$ overall, respectively (Figure 16).

In summary, the AE signals of layered concrete specimens mainly concentrate on the final fracture stage of the internal fracture of materials, while the $\mathrm{AE}$ signals of ordinary concrete specimens were concentrated in the nonlinear elastic stage of the formation of microcracks. Meanwhile, the layered concrete blocks exhibit low strength, a short duration of internal microcracking developing to form macrocracks, and sudden change from no macrofailure to instantaneous large-scale failure.

Based on the results presented in this paper, using $\mathrm{AE}$ technology to investigate the failure of concrete samples exposed to the effect of expansion pressure can give a better reflection of the mechanisms involved. Layering is an inherent feature of underground strata. In this work, a layered concrete test block was created based on strength similarity ratios. The static fracturing test performed on the layered block reveals, on one hand, the entire fracturing process, from the formation of microcracks to the damaging of the test block as a whole. Under actual conditions, the current cracking stage of the test block can be determined according to the characteristics of the AE event counts or AE energy parameters. On the other hand, performing similar static fracturing experiments on different concretes possessing different characteristics is important in guiding concrete research.

The experiments only focus on the AE characteristics of layered rock structure during static fracturing and preliminarily reveal the differences of layered concrete blocks containing layers of different strengths and diverse layered structures in terms of their static fracturing characteristics. In the future, the evolution of static deformation and fracturing of layered rock mass should be evaluated using high-resolution digital images of concrete and rock masses in the fracturing process in real time.

\section{Conclusion}

(1) The AE activity favorably reflects that the failure of concrete test blocks under expansion pressure comprises three stages: the microfracturing stage (elastic and nonlinear elastic stages), the transfer of expansion pressure stage, and the fracturing stage. It also reveals that the duration of static fracturing has a significant positive correlation with the overall strength change in the concrete.

(2) For ordinary-strength concrete, in the early fracturing stage, there is a sudden increase in AE activity. The most dramatic changes in AE energy and AE event counts occur mainly in the nonlinear elastic stage of the microfracturing stage, in which the $\mathrm{AE}$ event counts and AE energy reach their maximum values, accounting for $73.51 \%$ and $79.95 \%$ of the total counts during the static cracking process, respectively. The AE event counts and AE energy both increase first and then decrease during testing.

(3) For concrete test blocks with a soft interlayer and layered concrete test blocks, the AE event counts and $\mathrm{AE}$ energy both increase in the static fracturing process, while significant differences exist in the 
fracturing characteristics due to different strengths of the two layered concrete test blocks. AE event counts reach a maximum in the $\mathrm{C} 40-\mathrm{C} 10-\mathrm{C} 40$ test block (with a soft interlayer) in the transfer of expansion pressure stage, accounting for $47.11 \%$ of the total counts during the static cracking process; however, AE energy does not reach a maximum in the stage; for the layered concrete test blocks, largescale macroscopic failure mainly occurs in the fracturing stage, during which $\mathrm{AE}$ event counts and AE energy are the largest, being separately $76.22 \%$ and $66.94 \%$ of those in the whole static fracturing process.

\section{Data Availability}

The data used to support the findings of this study are available from the corresponding author upon request.

\section{Conflicts of Interest}

The authors declare that they have no conflicts of interest.

\section{Acknowledgments}

This research was funded by the National Natural Science Foundation of China (51874314), the China Postdoctoral Science Foundation (no. 2019M660861), the Guizhou Provincial Department of Education Youth Science and Technology Talent Growth Project (KY[2019]154), and the Guizhou Science and Technology Support Program ([2017] 2820). The authors are grateful to Dr. Jiarong Shen (Tsinghua University) for reviewing the original manuscript and for fruitful discussions.

\section{References}

[1] J. G. M. Van Mier, Fracture Processes of Concrete, CRC Press, Boca Raton, FL, USA, 2017.

[2] U. Ohlsson, M. Nyström, T. Olofsson, and K. Waagaard, "Influence of hydraulic pressure in fracture mechanics modelling of crack propagation in concrete," Materials and Structures, vol. 31, no. 3, pp. 203-208, 1998.

[3] A. R. Ingraffea, "Case studies of simulation of fracture in concrete dams," Engineering Fracture Mechanics, vol. 35, no. $1-3$, pp. 553-564, 1990.

[4] Y. Wang, S. Hu, X. Fan, and J. Lu, "Effect of water pressure on fracture parameters of concrete," Construction and Building Materials, vol. 199, pp. 613-623, 2019.

[5] N. Singh, M. Mithulraj, and S. Arya, "Influence of coal bottom ash as fine aggregates replacement on various properties of concretes: a review," Resources, Conservation and Recycling, vol. 138, pp. 257-271, 2018.

[6] R. De Silva, R. Pathegama Gamage, and M. Anne Perera, "An alternative to conventional rock fragmentation methods using SCDA: a review," Energies, vol. 9, no. 11, p. 958, 2016.

[7] M. P. Huynh and D. F. Laefer, "Expansive cements and soundless chemical demolition agents: state of technology review," in Proceedings of the 11th Conference on Science and Technology, Ho Chi Minh City, Vietnam, October 2009.
[8] J. A. Gambatese, "Controlled concrete demolition using expansive cracking agents," Journal of Construction Engineering and Management, vol. 129, no. 1, pp. 98-104, 2003.

[9] D. F. Laefer, N. Ambrozevitch-Cooper, M. P. Huynh, J. Midgette, S. Ceribasi, and J. Wortman, "Expansive fracture agent behaviour for concrete cracking," Magazine of Concrete Research, vol. 62, no. 6, pp. 443-452, 2010.

[10] C. B. Scruby, G. R. Baldwin, and K. A. Stacey, "Characterization of fatigue crack extension by quantitative acoustic emission," International Journal of Fracture, vol. 28, pp. 201-222, 1985.

[11] F. Du, K. Wang, G. Wang, Y. Jiang, C. Xin, and X. Zhang, "Investigation on acoustic emission characteristics during deformation and failure of gas-bearing coal-rock combined bodies," Journal of Loss Prevention in the Process Industries, vol. 55, pp. 253-266, 2018.

[12] E. Townend, B. D. Thompson, P. M. Benson, P. G. Meredith, P. Baud, and R. P. Young, "Imaging compaction band propagation in Diemelstadt sandstone using acoustic emission locations," Geophysical Research Letters, vol. 35, no. 15, p. L15301, 2008.

[13] J. Saliba, M. Matallah, A. Loukili et al., "Experimental and numerical analysis of crack evolution in concrete through acoustic emission technique and mesoscale modelling," Engineering Fracture Mechanics, vol. 167, pp. 123-137, 2016.

[14] R. V. Sagar, "A parallel between earthquake sequences and acoustic emissions released during fracture process in reinforced concrete structures under flexural loading," Construction and Building Materials, vol. 114, pp. 772-793, 2016.

[15] M. Ohtsu, M. Uchida, T. Okamoto, and S. Yuyama, "Damage assessment of reinforced concrete beams qualified by acoustic emission," ACI Structural Journal, vol. 99, no. 4, pp. 411-417, 2002.

[16] H. Cho, Y. Nam, K. Kim, J. Lee, and D. Sohn, "Numerical simulations of crack path control using soundless chemical demolition agents and estimation of required pressure for plain concrete demolition," Materials and Structures, vol. 51, no. 6, p. 169, 2018.

[17] L. X. Tang, C. A. Tang, and S. B. Tang, "Physics and numerical experiments of static crushing agent," Chinese Journal of Geotechnical Engineering, vol. 27, pp. 437-441, 2005.

[18] Expando, expansive mortar. Non explosive demolition agent used for rock, concrete breaking," 2016, http://www.expando. com.au/what-is-expando.

[19] H. Cho, Y. Nam, K. Kim, J. Lee, and D. Sohn, "Effective arrangement of non-explosive demolition agents and empty holes for improving fragmentation of square concrete structures," Journal of the Computational Structural Engineering Institute of Korea, vol. 30, no. 2, pp. 145-151, 2017.

[20] R. S. Yang, Z. H. Sun, Q. Tong, Y. X. Guo, and Z. W. Yue, "Experimental of crack propagation in test specimens under expansive of static cracking agent," Engineering Blasting, vol. 16, no. 3, pp. 7-11, 2010.

[21] Y. L. Dong, H. P. Xie, and Y. S. Li, "Acoustic emission characteristics and damage constitutive model of concrete under compression whole process," Mechanical Engineering, vol. 17, no. 4, pp. 25-28, 1995.

[22] H. Su, J. Hu, J. Tong, and Z. Wen, "Rate effect on mechanical properties of hydraulic concrete flexural-tensile specimens under low loading rates using acoustic emission technique," Ultrasonics, vol. 52, no. 7, pp. 890-904, 2012.

[23] S. X. Wu, Y. Wang, and J. Li, "Research on parameters in acoustic emission experiment of concrete under static uniaxial 
tension," Journal of Vibration and Shock, vol. 30, pp. 196-204, 2011.

[24] J. Geng, Q. Sun, Y. Zhang, L. Cao, and W. Zhang, "Studying the dynamic damage failure of concrete based on acoustic emission," Construction and Building Materials, vol. 149, pp. 9-16, 2017.

[25] Y. Zhang, G. Tan, S. Wang, Y. Cheng, S. Yang, and X. Sun, "Flexural characteristics evaluation for reinforced concrete affected by steel corrosion based on an acoustic emission technique," Applied Sciences, vol. 9, no. 8, p. 1640, 2019.

[26] M. J. Heap, Y. Lavallée, A. Laumann et al., "The influence of thermal-stressing on the physical, mechanical, and chemical properties of siliceous-aggregate, high strength concrete," Construction and Building Materials, vol. 42, pp. 248-265, 2013.

[27] F. Xiangqian, H. Shaowei, L. Jun, and W. Congjie, "Acoustic emission properties of concrete on dynamic tensile test," Construction and Building Materials, vol. 114, pp. 66-75, 2016.

[28] H. C. Li, The Similar Simulation Testing of Mining Pressure, China University of Mining and Technology Press, Xuzhou, China, 1998, in Chinese.

[29] Z. Z. Jin, H. Liao, W. Zhu, C. R. Ma, and Z. Q. Liu, "Splitting mechanism of rock and concrete under expansive pressure," Chinese Journal of Rock Mechanics and Engineering, vol. 8, no. 1, pp. 19-26, 1989. 


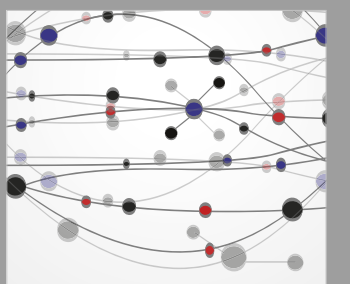

The Scientific World Journal
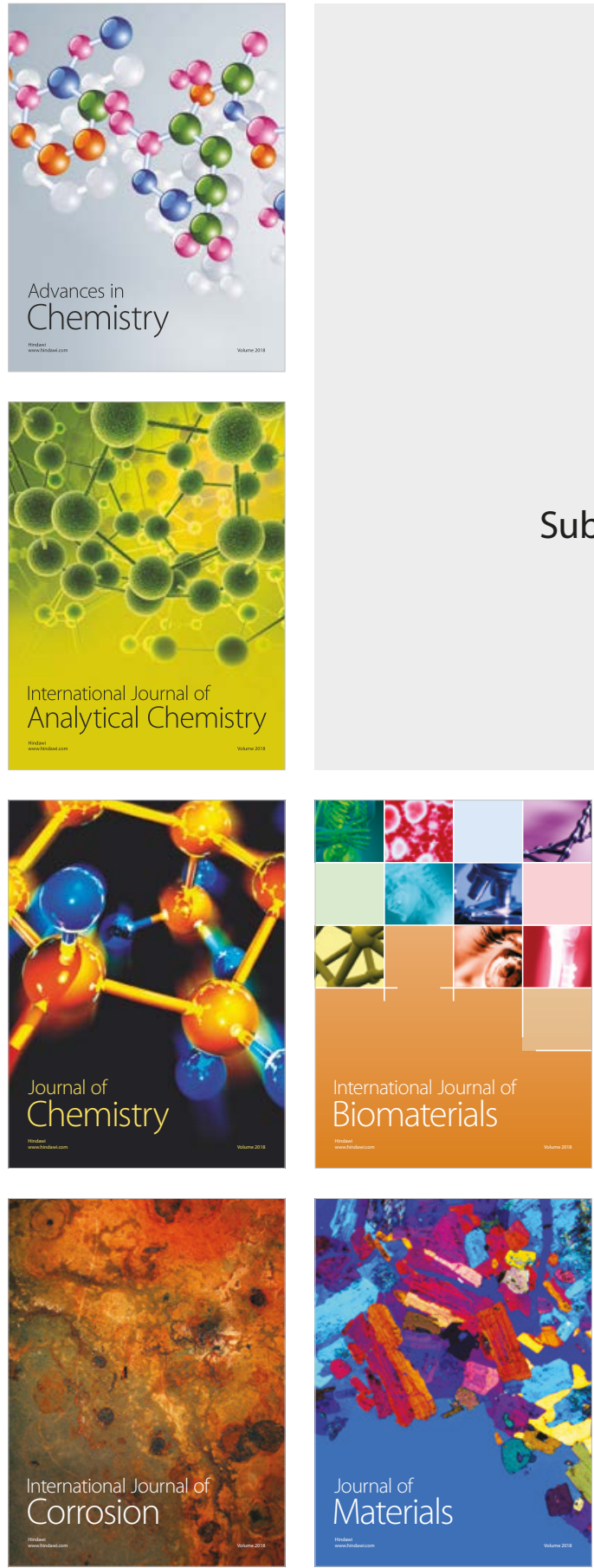

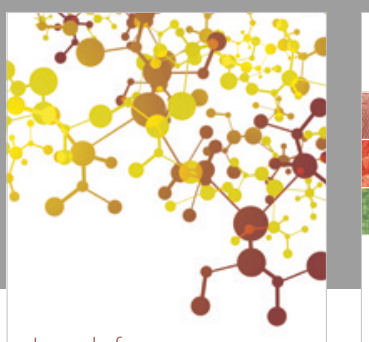

Journal of

Applied Chemistry
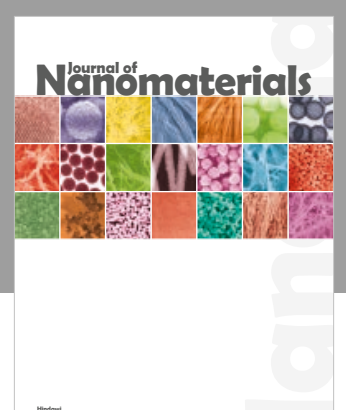

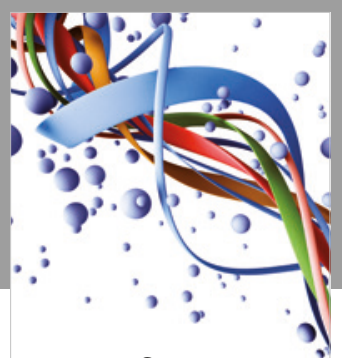

Scientifica

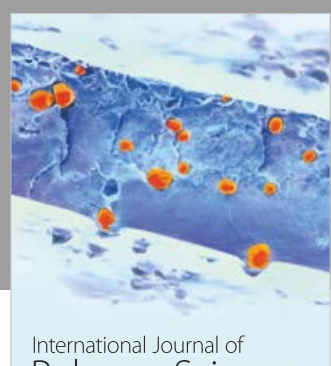

Polymer Science

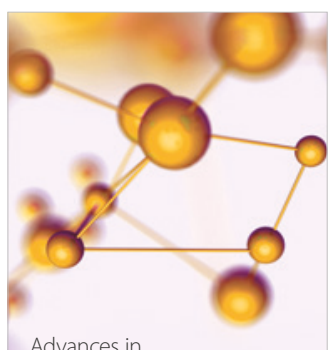

Physical Chemistry
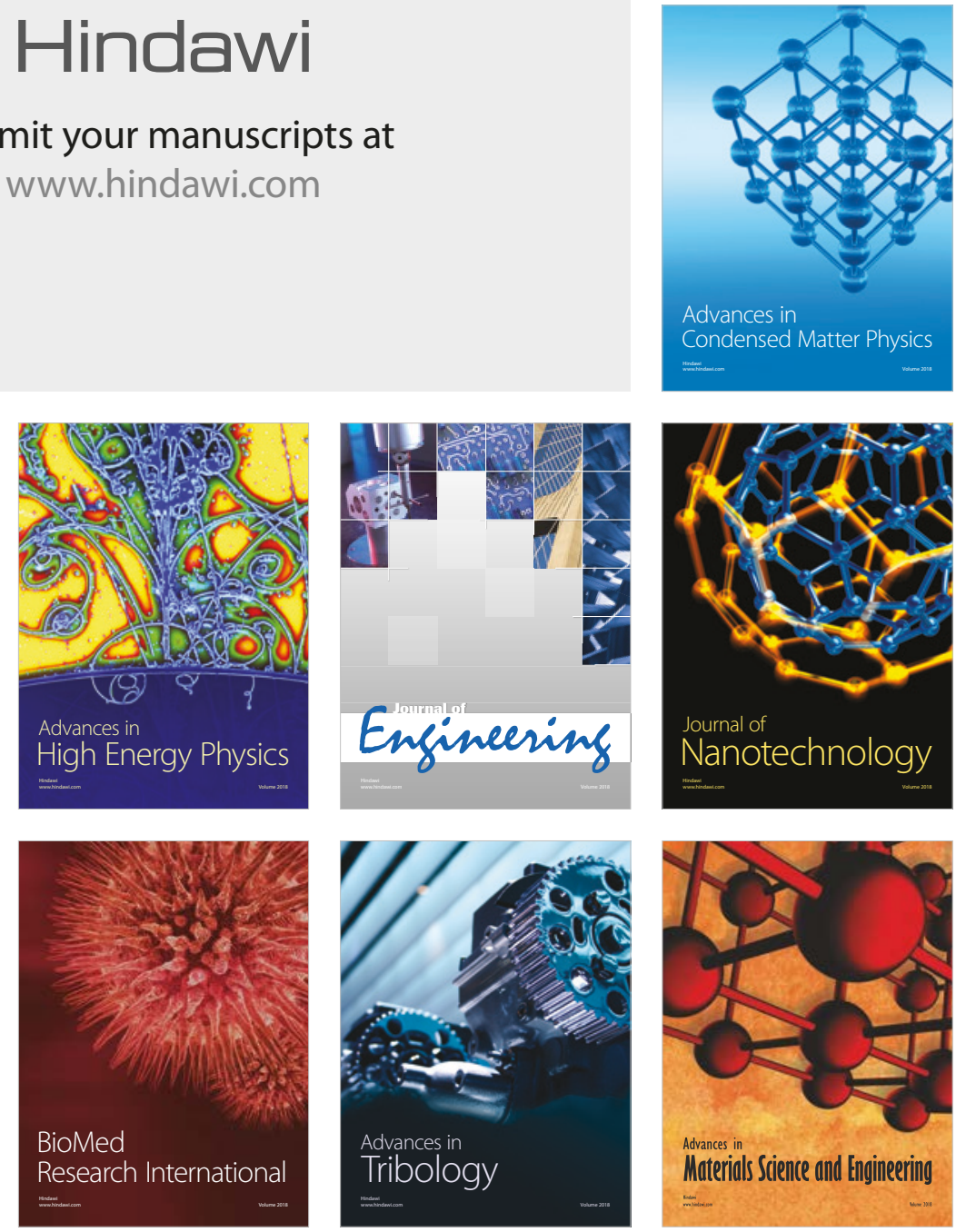